\title{
And mistrust take the hindmost: generalized trust in Denmark from 1990-2008
}

\author{
Morten Frederiksen \\ Department of Political Science \\ Aalborg University \\ Email:mfr@dps.aau.dk
}

\begin{abstract}
While most countries are experiencing stable or declining rates of generalized trust, this has not been the case in the Nordic countries, where levels of generalized trust have continued to increase. In the Danish case, trust increased by 50 per cent in the period from 1981 to 2008. This article investigates this puzzling development by testing the dominant socialization, status, and institutional theories on trust development. Using the Danish 1990, 1999, and 2008 waves of the European Values Study Denmark, the author employs graphical modelling in analysing the drivers of generalized trust increase in Denmark. Graphical modelling allows hierarchical structures of independent variables and is robust to thin cells, thus giving a more detailed picture than conventional regression techniques. The study shows that socialization has had little impact on the increasing level of generalized trust, whereas both individual achievement and the generally increasing levels of affluence and education are important drivers of the trust increase. However, since large parts of the population reaped the benefits of increasing levels of education and employment in Denmark during this period, this is not just a case of increasing trust, but also one of a diminishing low-trust minority excluded from partaking in this development.
\end{abstract}

Keywords: generalized trust, Denmark, graphical modelling, health, education, income 


\section{Introduction}

Contemporary research indicates that generalized trust is stable at a medium level in most western countries, while in others it is declining due to increasing inequality, individualization, institutional failure, and increasing heterogeneity (Delhey \& Newton, 2003; Fukuyama, 1996, 2001; Putnam, 2000; Robinson \& Jackson, 2001). Meanwhile, generalized trust in Denmark has been increasing despite increasing inequality and heterogeneity. Comparative research on generalized trust explains why trust is higher in Denmark than in many other countries. It does, however, tell us little about why trust is increasing. The purpose of this article is to conduct a single-case investigation of the Danish experience, investigating whether the theories and hypotheses predominantly used in explaining trust levels are helpful in understanding the Danish increase in trust. Analysing the Danish data from the three most recent waves of the European Values Study and employing graphical modelling, this study investigates how the increase in generalized trust has been differentiated between different parts of the population. From this differentiation, hypotheses are outlined on the relationship between the development of Danish society and the differentiated increase in generalized trust. In the conclusion these are reconnected to the predominant theories and the consequences for trust research are outlined.

Table 1: Responses to the question: 'Generally speaking, would you say that most people can be trusted or that you can't be too careful in dealing with people?' 1981-2008. Percentage. ${ }^{*}$

\begin{tabular}{lllll}
\hline & 1981 & 1990 & 1999 & 2008 \\
\hline 'Most people can be trusted' & 51.1 & 57.7 & 66.5 & 76.0 \\
'You can't be too careful' & 48.9 & 42.3 & 33.5 & 24.0 \\
\hline Valid N & 1061 & 992 & 986 & 1486 \\
\hline
\end{tabular}

* 'Don't know' responses comprise less than 4\% in 1990, 1999, and 2008. In 1981 they comprise $10.2 \%$ of the responses. However, there appears to be no systematic bias in the group choosing this response compared to the survey population on socio-economic variables. The 'don't know' responses are consequently ignored in this analysis. 
Table 1 shows the development in generalized trust in the Danish 1981, 1990, 1999, and 2008 waves of the European Values Study. There has been a significant increase in the part of the Danish population who consider other people to be generally trustworthy. This is interesting for two reasons. First, it is interesting in itself that the Danes' trust in other people has increased and that Danish society consequently experiences a value transformation on this issue, not least because other countries have experienced a decrease in generalized trust during the same period (Putnam, 2000). As can be seen in Figure 1, in many other countries levels of generalized trust have either been stable or in decline. Additionally, the Danish trajectory runs steadily upwards, while many other countries experience shifting increases and decreases. Secondly, it is interesting that levels of generalized trust can change so greatly within a relatively short time span. This gives rise to questions concerning what the characteristics of generalized trust are and how trust is established. A third question of interest is why Denmark experiences a trust development different from that of many other countries. That, however, is a question which cannot be addressed in a single-case study. Rather, this study may contribute to that discussion by questioning our theories about general trust, and thus help to develop a better scientific understanding of the dynamics of trust. 
Figure 1: Responses to the question: 'Generally speaking, would you say that most people can be trusted or that you can't be too careful in dealing with people?' in seven countries. $1-4^{\text {th }}$ waves of the European Values Study. Mean. ${ }^{*}$

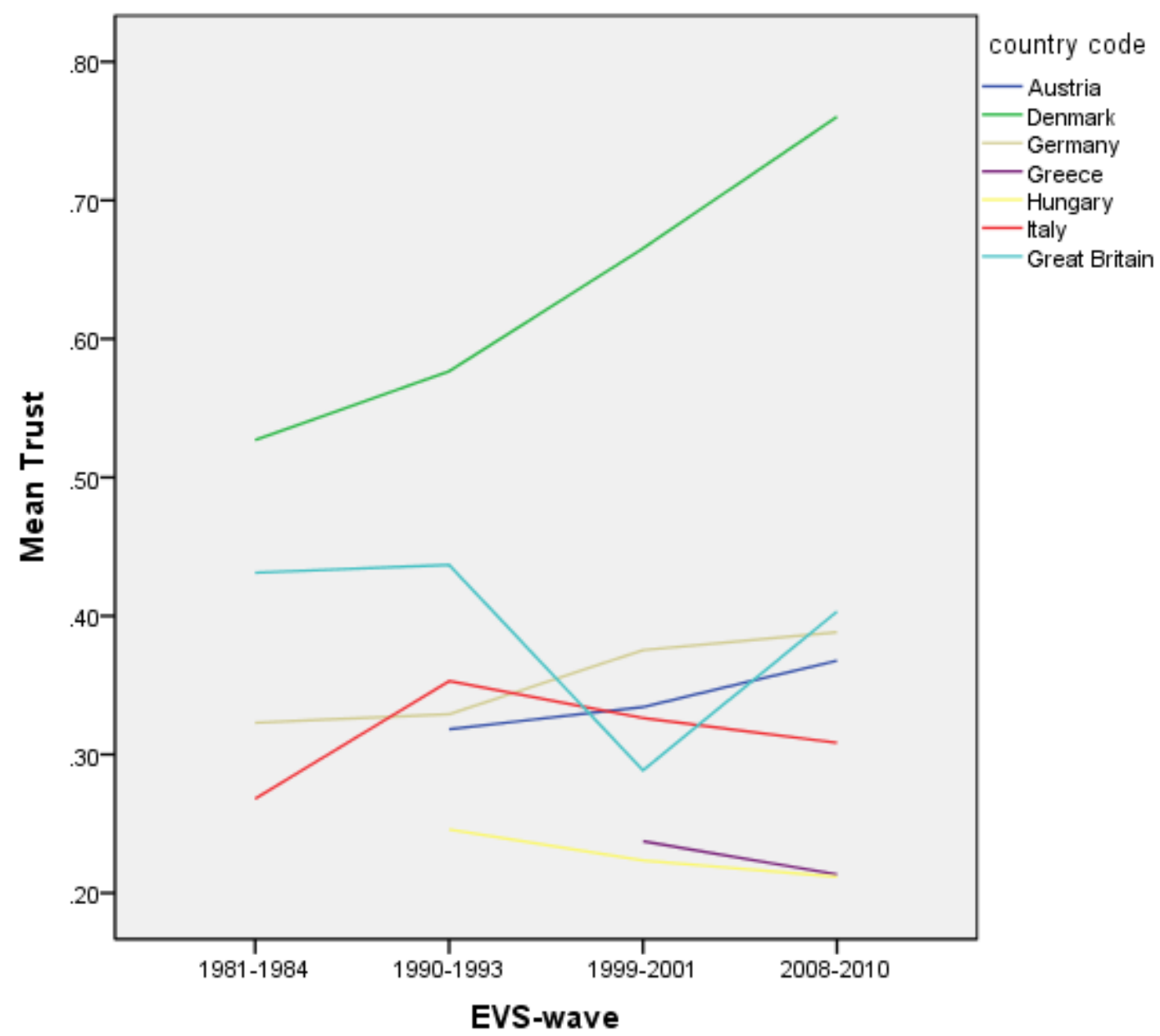




\section{Theories on Generalized Trust}

To be able to understand changes in the level of generalized trust, it is necessary to understand how it is created, maintained, and possibly lost. There are several different explanations regarding which characteristics, mechanisms and causes are important for generalized trust (Anheier \& Kendall, 2002; Bateson, 1988; Delhey \& Newton, 2003, 2005; Herreros, 2004; Kumlin \& Rothstein, 2005; Newton, 2004; Nooteboom, 2007; Rothstein, 2000; Rothstein \& Uslaner, 2005; Uslaner, 1999, 2000; van Oorschot, Arts, \& Gelissen, 2006).

Table 2: Six theories of generalized trust ${ }^{\star}$

\begin{tabular}{|c|c|c|c|c|c|}
\hline \multicolumn{2}{|c|}{ Individual theories } & \multicolumn{4}{|c|}{ Societal theories } \\
\hline $\begin{array}{l}\text { Personality } \\
\text { Theory }^{\star *}\end{array}$ & $\begin{array}{c}\text { Success-and- } \\
\text { well-being } \\
\text { theory }^{\star *}\end{array}$ & $\begin{array}{l}\text { Voluntary- } \\
\text { organization } \\
\text { theory }\end{array}$ & $\begin{array}{l}\text { Networks } \\
\text { theory }\end{array}$ & $\begin{array}{c}\text { Community } \\
\text { theory }\end{array}$ & $\begin{array}{l}\text { Societal } \\
\text { theory }\end{array}$ \\
\hline
\end{tabular}

*Adapted from Delhey and Newton, 2003. ${ }^{*}$ The theories in italics are part of the analysis in this article.

Jan Delhey and Kenneth Newton (2003, p. 94) classify these different explanations within six general theories (Table 2). These theories are subsequently divided into two groups depending on their theoretical point of departure. One group assumes that generalized trust is a characteristic of individuals and the way they relate to their social environs. The other assumes that the generalized trust of individuals is the product of or an aspect of societal structures.

This article investigates three of the abovementioned theories on generalized trust: the two individual theories and the structural theory named societal theory. It is the driving hypothesis of this article that such relatively significant changes in the level of generalized trust among the Danes have to be analysed and interpreted in connection with general changes in the way the individual Dane lives and experiences life, and the general conditions within Danish society. The three social-capital theories are excluded from this analysis for several reasons. First, because current research suggests that these theories cannot be substantiated empirically. Secondly, there are some 
theoretical problems in analysing social capital and trust within one model. We know that, empirically, volunteering, organization membership, and community involvement are correlated with generalized trust. Indeed, many social-capital theories define trust and civil society as constitutive parts in building social capital. Some argue that volunteering leads to increased levels of generalized trust, while others argue that generalized trust is a prerequisite for volunteering in the first place (Hooghe, 2008). A third position contends that people volunteer because they trust, but that civil society as a whole impacts society at large in a manner that fosters trust by engendering democratic values, political trust, and confidence in the political institutions in the generations to come (Newton, 2008). Theoretically, it is at this stage impossible to define a meaningful causal sequence between trust and volunteering, community activity or the general structure and strength of individual social networks. However, as Hooghe (2008) points out, the evidence supports the claim that people who trust volunteer, whereas the evidence is at best murky on the reversed causal relation. Consequently, I disregard social-capital explanations in this analysis, but this does not mean that social capital cannot, in one form or another, be an intermediary in the connections established in the analysis. However, the general consensus within current trust research is moving towards the position that civil society and social networks have limited impact on generalized trust (Rothstein \& Uslaner, 2005).

Personality Theory assumes that childhood socialization is the main source of generalized trust. According to this type of explanation, it is formative, early-life experiences of the trustworthiness of others, rather than experiences later in life, that influence the level of generalized trust in adulthood. The inspiration for this is Erik Erikson's theory about the importance of early childhood experiences to the experience of the world as a fundamentally benign place and the establishment of basic trust (Giddens, 1990, 1991; Möllering, 2001; Uslaner, 2002).

Success-and-Well-Being Theory focuses on the relationship between generalized trust and the experiences of adult life. This is not a psychological explanation but rather a status-based explanation. The theory makes the claim that successful people with high social status have higher levels of generalized trust, and conversely that unsuccessful people with low social status have lower levels. This claim rests on the assumption that those who have achieved success and high status can better afford the risks associated with trust and, 
furthermore, that they predominantly have had experiences that reinforce a trusting attitude. Conversely, those who are least successful and possess few resources are treated with the suspicion and lack of respect associated with low status. This in turn fosters suspicion within this group (Inglehart, 1999; Luhmann, 1980, 1988; Putnam, 2000; Stolle, 1998).

Societal Theory focuses on the characteristics of societies. Economic equality, the equity of institutions, and access to democratic participation are central elements of this type of explanation. Homogeneity is often emphasized, for example, the influence of ethnic homogeneity on generalized trust compared with ethnic polarization (Fukuyama, 1996; Inglehart, 1999; Knack \& Keefer, 1997; Kumlin \& Rothstein, 2005; Newton, 2001). It is important to note that, in this type of explanation, it is the characteristics of society and of the institutions within it that influence individuals and the way they regard each other. Consequently, generalized trust levels are not only explained by either equality or homogeneity; changes in the structure of society may also cause changes in generalized trust at both the general and the individual levels. The institutional element in these changes is of some theoretical significance to generalized trust, but most institutional impact is beyond single-case analysis. However, the individual level impact of large-scale institutional change can in some instances be captured within single-case analysis. The theoretical focus here is, consequently, how structural transformations in society impact individual-level characteristics.

The three theories are presented in Table 3, which shows three different characteristics of each category of explanation. First, the category source of trust describes the element which is claimed to affect whether or not people have generalized trust. Secondly, explained differences refers to the types of differences in generalized trust levels which the theory is primarily focused on. Finally, type of reproduction describes the way generalized trust is argued to be created and maintained; this predominantly concerns how the source of trust is reproduced. 
Table 3: Generalized trust: comparing the three theories

\begin{tabular}{|c|c|c|c|}
\hline Theory & Source of trust & Explained differences & $\begin{array}{l}\text { Type of } \\
\text { reproduction }\end{array}$ \\
\hline Personality & $\begin{array}{l}\text { The psychological } \\
\text { constitution of the } \\
\text { individual }\end{array}$ & Between individuals & $\begin{array}{l}\text { Childhood } \\
\text { socialization }\end{array}$ \\
\hline $\begin{array}{l}\text { Success } \\
\text { and well- } \\
\text { being }\end{array}$ & $\begin{array}{l}\text { Resources } \\
\text { facilitating trust, } \\
\text { experiences } \\
\text { confirming trust }\end{array}$ & $\begin{array}{l}\text { Between individuals } \\
\text { and status groups }\end{array}$ & $\begin{array}{l}\text { Successful or } \\
\text { adverse } \\
\text { experiences } \\
\text { associated with } \\
\text { socio-economic } \\
\text { position }\end{array}$ \\
\hline Societal & $\begin{array}{l}\text { Equity, equality, and } \\
\text { absence of conflict }\end{array}$ & $\begin{array}{c}\text { Between nations and } \\
\text { societies, and over } \\
\text { time }\end{array}$ & $\begin{array}{c}\text { Cultural, economic } \\
\text { and institutional } \\
\text { structures }\end{array}$ \\
\hline
\end{tabular}

Table 3 may also give an indication of some of the problems involved in distinguishing between the causes and the effects of generalized trust. For instance, success and well-being in life are equally as likely to be the consequences of having trust in other people as they are to be the cause thereof. It is therefore important not to conceptualize trust as part of a simple causal chain of events in which it is either a cause or an effect of other social phenomena (Lewis \& Weigart, 2012). Rather, generalized trust should be conceived of as part of a process of reproduction in which trust and other elements are mutually reinforcing. In other words, generalized trust is not just an attitude more or less firmly embedded in people's perceptions, guiding the way they relate to other people and perceive them: it is also a characteristic of the societal process (Frederiksen, 2012; Uslaner, 2002). When upbringing, life-experience, and social environment are characterized by cooperation and reciprocity, these are related to the level of generalized trust in society in general (Hardin, 2002; Luhmann, 1979). Generalized trust enhances the individual's ability to cooperate within a variety of social contexts. Simultaneously, it is only through experiences with cooperation and reciprocity that trust is possible within these different contexts (Hardin, 2002). When the level of generalized trust in different countries can change relatively 
significantly within a short period, it is because it is not something an individual conclusively possesses. Rather, it is reproduced and maintained continually, and social changes may disturb its reproduction (Frederiksen, 2012).

Building from each of these theoretical approaches, I propose three hypotheses concerning the development of generalized trust in Denmark:

1. The development of the patterns in the levels of generalized trust is a consequence of changes in the prevalent patterns of socialization within the population.

2. The development of the patterns in the levels of generalized trust is a consequence of changes in both the level and experience of success and well-being within the population.

3. The development of the patterns in the levels of generalized trust is a consequence of structural changes in the demographics and socio-economic conditions of the population.

\section{Data}

The study was based on the Danish 1990, 1999, and 2008 waves of the European Values Study. The selection of this particular survey was grounded in the following facts: the survey is longitudinal; it includes a very recent cross-section; it is a well-tested, high-quality survey conducted by skilled interviewers making house-call interviews, and it includes a rather large section on socio-economic background. Though not as good as a survey crafted specifically for the purpose at hand, the Danish EVS survey was by far the best suited compared with other available data (ISSP, ESS).

The survey populations of the Danish EVS waves were random selections of people aged 18 years and above drawn from the Danish Civil Registration System. People in prison, people with no known address, people listed as living abroad, and those with so-called research protection (i.e., people who have informed the authorities that they do not accept contact from researchers) were excluded. The number of completed survey interviews was 1030 in 1990 with a response rate of 75 per cent; 1023 in 1999 with a response rate of 58 per cent; and 1507 in 2008 with a response rate of 51 per cent. Response rates are calculated on the basis of all members in the 
sample (Christensen \& Gundelach, 2011). The 1990-1999 questionnaire deviates from the version used in 2008 by including only one binary item on generalized trust from the Rosenberg set of five items, which is consequently the only item available for longitudinal analysis.

\section{Method}

Graphical Modelling is employed in the multivariate analysis of longitudinal data from the four cross-sectional data sets. This is a multivariate statistical model in which causal relations between variables can be symmetrical, traditional (dependent/independent), and block recursive (in which a chain of variables are assumed to be ordered causally). The correlations between variables are controlled for conditional independence (whether correlations with other variables within the model account for the correlation between the two tested variables). The modelling procedure places the variables in a block-recursive structure called the independence graph, from which correlation coefficients of every relationship in the model are calculated. The statistical procedure behind the test for conditional independence is a log-linear analysis. The test statistics used are either a $\chi^{2}$-test if the correlation is non-linear or, predominantly, a $Y$ test in the case of linear correlations. In both cases a Monte Carlo estimate of the $p$-value is used to obtain robust estimates (Demant \& Østergaard, 2007; Gundelach \& Kreiner, 2004; Kreiner, 1987, 1996).

In the process of testing the model, relationships between variables are excluded as they prove conditionally independent. This type of analysis provides a number of advantages compared with traditional regression techniques. First of all, it is suited for analysing both nominal- and ordinal-scale variables, which most variables in the EVS are. Secondly, a large number of independent variables can be included in the analyses and they can be assigned positions in chains as both dependent and independent. Thirdly, the analysis is directed at elaboration and explanation rather than causality. Fourthly, the method is robust to low-count cells. Finally, the graphical model allows the research to handle a more complex modelling process without losing track of theory, hypothesis or assumptions (Christensen \& Gundelach, 2011). 


\section{Model}

The purpose of this single-country analysis is to identify and differentiate the causes of the increase in the levels of generalized trust in Denmark. Theoretically, the point of departure is from the different causal drivers of generalized trust proposed by personality theory, success-and-well-being theory, and societal theory, and the three associated hypotheses set out above.

The three hypotheses and the associated theories assign quite different roles to generalized trust, and consequently different explanatory relations. Significantly, personality theory and successand-well-being theory are incompatible on this point. Personality theory claims that generalized trust is established at an early point in life and is therefore less influenced by, for instance, education or marital status. Conversely, the theory of success and well-being assumes that it is precisely income, health, and marital status that may influence generalized trust. Following societal theory, the sequence of different variables depends on whether one assumes that structures and institutions primarily work through socialization, or that a continued influence and selection process accounts for generalized trust. In other words, is education the cause of generalized trust or is it the effect of it? In modelling the analysis, the answer to this question is pragmatic. It is not a necessary assumption in testing personality theory that generalized trust influences choice of education, income or marital status, whereas it is a necessary condition of testing successand-well-being theory that income, marital status, and education can influence generalized trust.

The consequence of this choice is that the model is biased towards the theory of success and well-being. However, bivariate analysis shows significant changes in generalized trust within cohorts, which indicates that generalized trust is not simply set in childhood, but may also change throughout life. This supports the modelling choice of allowing trust to be a dependent rather than independent variable in relation to variables describing experience and life course, such as education. 
Table 4: The three hypotheses and the associated variables.

Hypothesis Independent variables

Personality hypothesis: Gender, Birth cohort

Success-and-well-being hypothesis: Number of children, Self-reported health, Employment, Marital status, Income.

Societal hypothesis: Urbanization, Age, Education

The operationalization of each hypothesis is limited by the available data. While additional data are available in the 2008 cross-section, the information relevant to the personality hypothesis is limited to gender and birth cohort in the longitudinal data set. These items give good information on differences the dominant patterns of socialization to which people have been subjected. However, important information is lacking, including information about parents' education or the socioeconomic childhood conditions. Consequently, social reproduction of income and educational attainment may conceal socialization effects as either success-and-well-being effects or societal effects. The data relevant to the success-and-well-being hypothesis are more comprehensive. Information about children, marital status, health, employment, and income cover the more important areas of attainment within adult life. Finally, the amount of data relevant to the societal-impact hypothesis is also somewhat limited. Urbanization is a process that changes the dominant structures of settlement, work-life balance, communities, and so on, at a societal level. Similarly, age is a proxy for the institutional structures characteristic of specific life stages; while age in itself should not be expected to influence trust levels, the type of experiences and the level of support afforded by society depends very much on age. Education is also primarily an indicator of structural change rather than individual attainment. While the specific choice of education may express important individual characteristics, the number of people who get trained as a skilled craftsman compared with the number who get a master's degree is very much a question of societal structure. The data are here limited to a very specific subset of societal-level characteristics measured at the individual level. While other macro-level characteristics are often included in comparative analyses, these cannot be included in this type of single-case analysis. Consequently, the analysis in this article 
may underestimate the full institutional and structural impact on trust development.

\section{Analysis}

The following analysis is based on a statistical modelling of the EVS data from 1990, 1999, and 2008, in which relevant variables have been included and excluded as independent variables influencing generalized trust. The three hypotheses are addressed in one model, but in the process of finding the right model, two separate search strands have been followed in order to avoid multicollinearity: one including age and another including birth cohort. The reported correlations are derived from the cohort model - with the exception of age - as this model turned out to be the best fit to data. The three hypotheses are presented with the relevant variables in Table 4.The results of the model search are reported in Tables 4 and 5 .

None of the three hypotheses emerges as the better explanation of generalized trust; rather, the analysis supports a combination of the hypotheses. Education and survey year turn out to be the dominant variables in the model, but the respondents' perception of their own health also significantly influences the level of generalized trust. Furthermore, income and birth cohort are correlated with generalized trust, but, even though significant, the coefficients are relatively low. The variables of urbanization, marital status, number of children, employment, gender, and age all show low and insignificant correlations with generalized trust. 
Table 5: Partial, direct $\mathrm{y}$-correlations to generalized trust (19902008)

\begin{tabular}{l|ll}
\hline Variable & Partial Y-correlation & Significance $(P)$ \\
\hline Urbanization & 0.03 & 0.297 \\
Employment & 0.00 & 0.504 \\
Marital status & 0.04 & 0.233 \\
Self-reported health & 0.21 & 0.000 \\
Number of children & 0.02 & 0.362 \\
Income & 0.13 & 0.003 \\
Education & 0.34 & 0.000 \\
Gender & 0.02 & 0.335 \\
Birth cohort* & 0.02 & 0.272 \\
Age & 0.03 & 0.351 \\
Survey year & 0.32 & 0.000
\end{tabular}

${ }^{*}$ The correlation between birth cohort and generalized trust is insignificant in the gamma test, but this is caused by a non-linear correlation. $A \chi^{2}$-test shows a significance of $p=0.027$.

Turning to the indirect correlations in Figure 2, we see that the temporal changes from 1990 to 2008 are primarily directed at the level of education and the level of employment, apart from the direct correlation with generalized trust. Additionally, employment is strongly linked to temporal change, since time and employment are correlated both directly with and mediated through the differential level of employment across birth cohorts. However, employment does not directly drive the trust levels, but has a more moderate, mediated effect through health and income. Additionally, a correlation appears between urbanization and education. However, both the healthemployment and the education-urbanization correlations are situated within the same recursive block and, consequently, the causality is 
unclear. Finally, there appears to be an unsurprising causal relation between gender and level of education, showing that there is a gender impact on generalized trust, mediated by the level of education. This suggests that education, rather than gender, accounts for the difference between genders in level of trust.

The interpretation of these results is made difficult by the continued significance of survey year, because this correlation expresses the variance, unexplained by the model, in the changing levels of generalized trust from 1990 to 2008. This correlation could arguably be interpreted as a period effect on the increasing level of trust, which is not differentiated between groups but affects the entire society. It is, however, equally plausible that the relevant data needed to account for this increase is unavailable in the dataset. The model search has been much more encompassing than presented here, but with similar results.

Nonetheless, the analysis indicates some significant correlations. The contributions of education, income, and perceived health are of a magnitude that may help to explain the increase in generalized trust. It is also worth noting that the correlation between generalized trust and birth cohort is significant, if small. This suggests that the personality theory cannot be dismissed completely. In the following sections I shall deal initially with education and income, and secondly with health. 


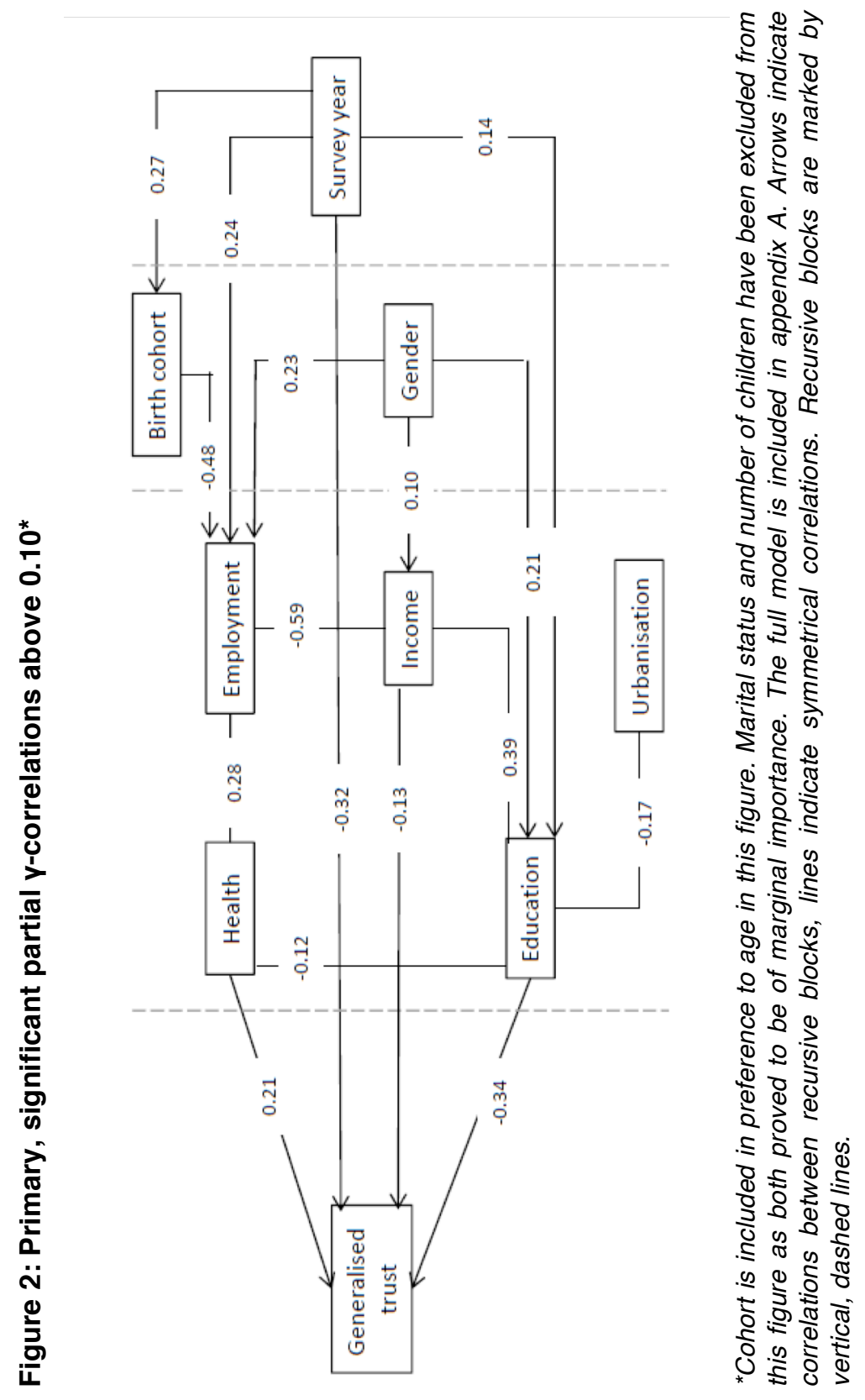

NJSR - Nordic Journal of Social Research 


\section{Education}

The main finding is that education heavily influences the level of generalized trust, confirming the findings of other studies on this issue (Delhey \& Newton, 2005; Paxton, 2007; Rothstein \& Uslaner, 2005; Yamagishi, 2001). According to both individual-level theories, generalized trust is associated with a perception of the world as fundamentally cooperative and dependable. It is assumed that generalized trust develops from experiencing the social as generally comprehensible and unthreatening. Education may greatly influence the perceptions of social relations and activities in that direction. Furthermore, increased levels of education may also contribute to the development of skills and reflective competences that allow one to navigate social relations, harvesting experiences that confirm generalized trust outside in-group relations (Edwards, Ranson, \& Strain, 2002).

The model indicates that it is changes in the level of education, rather than the success-and-well-being effects of increased education (income and employment), that lead to increases in generalized trust. The indirect correlation between survey year and generalized trust, by way of education, supports the idea that the increases in the level of trust are driven by changes in educational level. The multivariate analysis suggests that education with academic content (ISCED 3 and above) has an influence on the level of generalized trust. The increase in generalized trust from 1990 to 2008 appears to be partially explained by the increase in the part of the population with an academic education, along with a decrease in the part with only primary education or an education as a skilled labourer during this period (Table 6). The change in relative size of the populations with the two types of education is quite significant, supporting the hypothesis that the societal changes in the educational system are leading to increasing levels of generalized trust. This is supported by a moderate correlation between survey year and education $(\gamma=0.14$, $\mathrm{p}=0.000$ ). 
Table 6: Population distribution of highest completed education between primary school/vocational training and tertiary education, in percentages. $(1990,1999$, and 2008)

\begin{tabular}{lccc}
\hline & 1990 & 1999 & 2008 \\
\hline $\begin{array}{l}\text { Primary school/vocational } \\
\text { training }\end{array}$ & 69.1 & 56.9 & 51.8 \\
Tertiary education & 30.9 & 43.1 & 48.3 \\
Valid N & 1030 & 1022 & 1498 \\
\hline
\end{tabular}

The Danish population is increasingly participating in longer, more academically structured types of education, and society and social relations may seem more comprehensible and unthreatening as a consequence (Luhmann, 1979). This leads to increased generalized trust in large parts of the population, while the remaining minority of the population has less formal education and lower levels of generalized trust. While accounting for some of the increase in generalized trust, this development cannot explain why there has been an increase in generalized trust within all groups independently of education.

A more detailed analysis of conditional independence within thirdvariable strata shows that the correlation between education and generalized trust is intersected by birth cohorts. Combining generalized trust, education, and birth cohort reveals a new picture. The cohorts that grew up after the Second World War are more trusting than the preceding cohorts, and, from 1990 and onwards, their generalized trust increases. This development can also be traced in the data from 1981, although here information on education is less differentiated. In these post-war cohorts it is particularly those with longer academic educations who are more trusting, while trust in the older cohorts is more evenly distributed between educational categories. The well-educated young and middle-aged people experience an increase in generalized trust to a greater extent than others from the same cohorts, while also being subject to the increase in generalized trust associated with academic education. Furthermore, they appear to maintain this trust level even after retirement. This pattern cannot be found among the older cohorts, where trust levels 
are less dependent on level of education and do not increase at the same rate from 1990 to 2008. Consequently, it would seem that the education effect on trust is stronger at the highest level of education and, furthermore, that the effect has changed over time, making tertiary education a stronger driver of trust in younger cohorts than in older ones. In addition, the differences between birth cohorts suggest that the increase in trust from 1990 to 2008 may in part have been caused by mortality in the older cohorts.

\section{Income}

The correlation between income and generalized trust is significant, supporting the hypothesis of success and well-being. The influence of income supports the assumption that that the protection against the uncertainties of life that can be provided by money contributes to increases in generalized trust. Furthermore, a certain level of income also increases freedom of action and self-efficacy (Uslaner, 2002). However, the correlation is weak to moderate, which is somewhat surprising. The multivariate model shows that any impact of employment on trust is partly mediated through income $(\gamma=0.59$, $p=0.000$ ). This strong correlation is primarily the difference between employment and unemployment in terms of income. Between 1990 and 2008 there was a marked decrease in the level of unemployment, as shown in Figure 3. This difference in employment rate has had an impact on trust mediated through income. Since the causal direction would primarily be from employment to income, changes in employment status will contribute significantly to the trust-income correlation. There is, in other words, an indirect connection between the trust-income correlation and the changing trust levels from 1990 to 2008 by way of increasing employment rates. 
Figure 3: Full-time unemployed, in percentage of workforce (1990 to 2008)

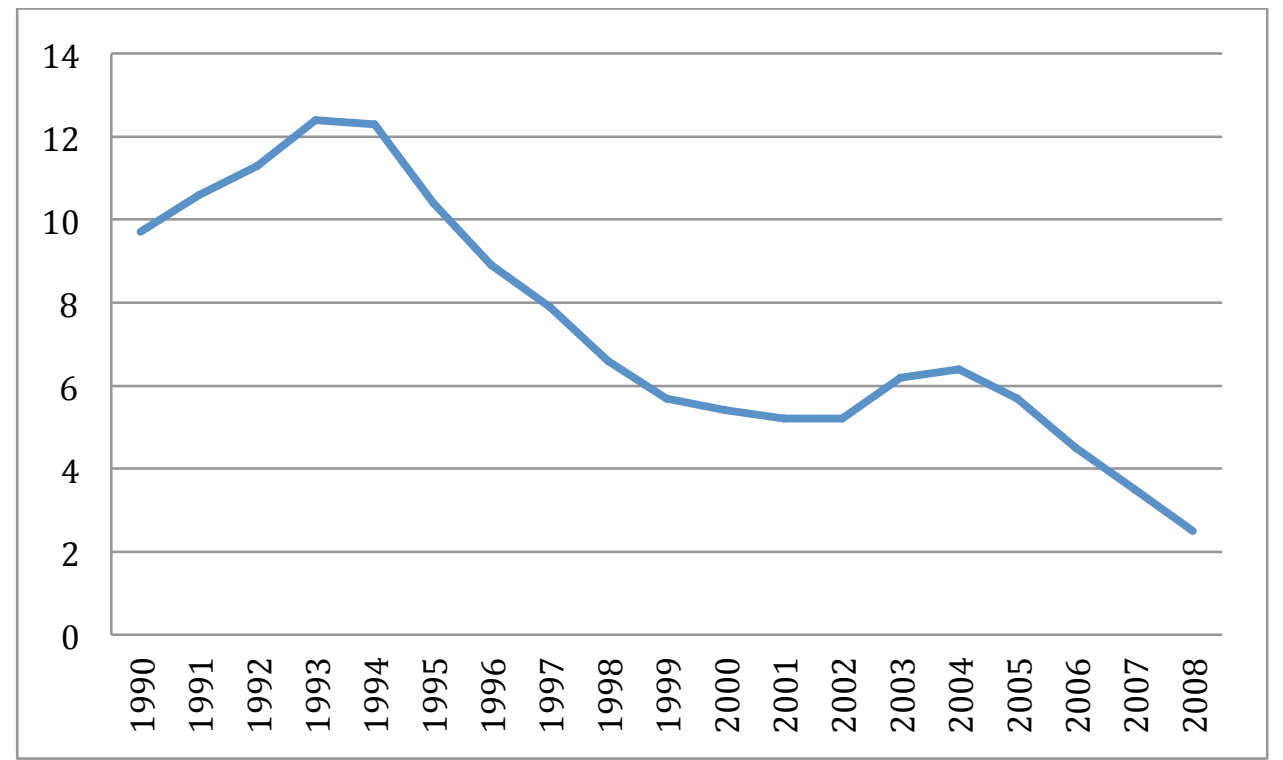

Source: Statistics Denmark

An examination of the trust-income correlation for conditional independence across third-variable strata leads to some interesting results. It turns out that there are confounding effects involving health, education, and birth cohort, suggesting that the correlation is stratified rather than homogenous. First, the positive correlation between income and generalized trust seems to hold true among those with unskilled, skilled, and short- or medium-length tertiary education. However, among those with a long tertiary education (ISCED 5) the correlation is reversed: the more money they make, the less they trust. While the overall level of trust among the highly educated is high, those with higher incomes have a relatively lower level of trust than those with lower incomes. Secondly, while the positive correlation between income and trust holds true for most birth cohorts, this is not the case among the youngest cohort. Here the correlation is reversed, making the youngest with the lowest incomes relatively more trusting than those with higher incomes. Finally, the correlation between trust and income is intersected by perceived health. While the correlation remains positive in most of the categories on the health measure, it disappears among those with the poorest quality of health. For this group, income does not matter in regard to trust. The general picture, 
then, is that while increasing income does have some impact on the trust level, this is not a homogenous correlation. The reversed correlation among the younger cohorts is presumably related to the low income of the students and the relatively higher income of those who enter the labour market earlier in life. This accounts for some of the correlation between income and employment. The reverse correlation between income and trust among the highly educated may be the result of the differences between the different kinds of higher education - either in terms of educational content or in terms of the employment environment.

\section{Health}

The self-reported state of health is also correlated with the level of generalized trust, as can be ascertained from Table 5. On closer inspection, this correlation is independent of all variables other than birth cohorts. People experiencing a good or very good state of health are predominantly trusting, people experiencing a fair or poor state of health are marginally more mistrustful than trusting, and people experiencing a very poor state of health are predominantly mistrustful. This correlation is similar to the correlation between education and generalized trust, only with the opposite outcome. A very poor state of health may result in the perception of society in general as a less friendly place, providing fewer experiences that support trust and generally making social relations less easy to manage and navigate. Furthermore, research indicates that trust is strongly correlated with self-efficacy, which is markedly lowered by poor health (Frederiksen 2012). The close connection between socio-economic limitations and a poor state of health conceivably makes this correlation the downside of the positive correlation of trust with income and education (Kawachi, Kennedy, \& Glass, 1999; Vicky, 2001; Whelan \& Whelan, 2004). It is primarily those with poor health from among the disablement pensioners, those on early-retirement allowance, the retired, and the unemployed who have low levels of trust. The influence of a poor health on generalized trust cannot be explained by education, age, cohort, or employment, even if health is strongly correlated with employment $(\gamma=0.28, p=0.000)$. However, the influence of poor health on generalized trust is also present among the employed. Full-time employment and higher levels of education seem to be partially negating the influence of experienced health on generalized trust, since those with higher education and full-time employment only express low levels of trust if they experience their 
health as being very poor. This supports the connection between health, self-efficacy, and generalized trust. However, since there is no direct connection between survey year and health, the impact of the experienced quality of health on generalized trust is quite stable from 1990 to 2008. The indirect influence of survey year on health mediated by employment may indicate that any temporal effect on the trust-health relation is better described in terms of employment. Furthermore, the strong correlation between health and employment may be deceptive in this regard since the causality is bi-directional.

In summary, self-reported health has a significant influence on generalized trust but cannot help us to understand the increase in generalized trust. It can, however, help us to understand why some groups express a higher level of generalized trust than others. The unequal distribution of health, in which certain disadvantaged groups report a disproportionately high level of health problems, is probably part of the reason why the old, those with little education, the unemployed, the disablement pensioners, those on early-retirement allowance, and the retired do not experience the same increase in generalized trust as all other groups do.

Generally, the reported correlation between income and generalized trust supports the theory of success and well-being since increased income leads to increased trust in most cases. However, elaborating with the education variable revealed that this general trend does not hold within the highest level of education. For those with the highest level of education, the trend is reversed, suggesting that either the impact of income on trust wears out at a certain income level or that other factors associated with high income and high education are at work. Since the correlation is not only reduced, but in fact reversed, the latter explanation seems the more probable.

Finally, education turns out to be the strongest driver of trust levels in general, as well as the specific increase in generalized trust in Denmark from 1990 to 2008. This supports the societal theory, since the structural changes in education in Denmark have resulted in a general increase in level of education and, consequently, an increase in generalized trust. 


\section{The Trusting Danes}

The general picture drawn by this analysis is that the Danish population has a high level of generalized trust and that the level has been increasing throughout the studied period. Among the people with the least education, lowest income, poorest health, and with deceased spouses, generalized trust is much lower than the population average. This is particularly true of those experiencing combinations of these characteristics. Consequently, the theory of success and well-being must be revised to fit the Danish case. As a consequence of the general positive development within levels of education, income and employment in Denmark, the default attitude is one of high levels of generalized trust. Thus a more precise theory or hypothesis to describe the Danish case would be a theory of misfortune indicating the types of adverse experiences and conditions which seem to lower generalized trust or prevent it from increasing. Early retirement, disability, unemployment, old age, or limited education reduces the available courses of action and leads to lower levels of access to economic, cultural, and social resources. Rarely (or sometimes never) do they have the possibility of participating in society on equal terms with the population average. This is supported when we look at other parts of the survey showing that those with low generalized trust also express less self-efficacy and less happiness than the population average.

The high level of generalized trust in Denmark suggests that the success-and-well-being hypothesis is incorrect in this instance. Success is a relative phenomenon which loses meaning when most people have achieved it. Among those with the fewest resources, generalized trust is at its lowest. Generalized trust is contingent upon having access to economic, cultural, and social resources, rather than the level of access. Belonging to the richest and best-educated elite or to the large middle class is of far less significance to generalized trust than being employed and having more than a basic level of education. This questions some of the usual assumptions about trust and equality. It is usually argued that generalized trust depends on economic equality because this decrease the relative distances between different social groups (Uslaner, 20002). The misfortune theory would indicate that economic equality drives trust because it lifts a larger proportion of the population above the threshold of disempowerment - at least within relatively affluent societies. However, we should expect the threshold of disempowerment to be placed differently in different countries depending on institutional 
make-up. The Danish case places the threshold at the margin of compound exclusion, but this is presumably linked to universal welfare institutions. Divorce, lower levels of education or poor health should be expected to lower trust levels even among the employed in countries where institutional backing is less readily available.

Apart from the importance of success and misfortune, the analysis also supports both societal and personality theory. In itself, birth cohort does not strongly influence generalized trust in the model, but it does intersect with both education and health in influencing generalized trust. With these quite significant changes in the level of generalized trust, personality theory seems an unlikely explanation. Generalized trust as a part of personality and socialization would be quite stable from an early point in life, which is not the case according to this analysis. We may, however, imagine another way in which generalized trust and socialization can be linked. Since birth cohort is correlated with both education and self-reported health, the influence of socialization and personality is not so much directly on generalized trust, but rather on the way changes within society and individual life come to bear on generalized trust. Socialization and the development of personality in early life may greatly influence the ways in which life and society are interpreted, and consequently sustain or suppress the development of generalized trust from experiences of affluence, safety, increased levels of education, and so forth (Mannheim, 1952; Pilcher, 1994). Growing up in a period of economic growth, with employed parents, reasonable housing, and so on leads one to take options and resources for granted, confirming a perception of the world as a friendly and cooperative place. Conversely, growing up in want and insecurity will not lead one to take options and resources for granted, nor readily to assume the cooperation and good intentions of others, despite increases in available economic, social, and cultural resources. The general increase in generalized trust from 1990 to 2008 is best accounted for by a period explanation positing the socioeconomic development from 1990 to 2008 as the primary driver of changes - specifically, increasing levels of both employment and education. However, the differences in the increase of generalized trust between birth cohorts indicate that a cohort explanation should also be applied in order better to understand why this socio-economic development may have had different impacts on different birth cohorts, particularly between the pre- and post-war cohorts (Inglehart, 1971, 2003). 
The analysis gives the strongest support to the societal theory, since education is the most strongly correlated independent variable with respect to generalized trust. Changes in educational structure and uptake have taken place since the end of the Second World War, and these changes are strongly reflected in the differences between cohorts. Consequently, over time the general educational level and composition of the population changes significantly. Education helps to build generalized trust since it - and particularly academic education with a focus on analytical and abstract competencies makes people more skilful in navigating and understanding complex social environments. The significant increase in the average level of education from 1981 to 2008 is in itself an important factor in the increasing level of generalized trust. An increasing number of people command skills that are helpful in developing and sustaining generalized trust. Furthermore, the intersection of birth cohorts in the correlation between generalized trust and level of education expresses the changing influence of education on generalized trust between cohorts. This may be assumed to rest on the mutually reinforcing influence of both increased education and positive socioeconomic development on the post-war cohorts. However, it may also be the result of the changes in curriculums, didactics, and institutional structure within the educational system that have taken place since the Second World War. The development of the educational system has not just meant that more people have received a higher education, but also that the abstract and analytical competencies formerly associated with higher tertiary education are now also taught at the lower levels of tertiary education (Hansen \& Gleerup, 2004). Consequently, the shift towards higher levels of education takes place not only as movement between categories of education, but also as a general development in the educational system. What remains is the somewhat discouraging result that increases in affluence, employment, and education have benefitted only the majority, leaving behind a minority of 'mistrusters' who do not share the positive outlook that seems to prevail within the population in general. For this minority, this 18-year period has passed without leaving much of a mark. In the period from 1985 to 2007, economic inequality increased from a Gini-coefficient of 0.2209 to 0.2478 (Source: OECD). While some of this increase was driven by rising real-estate prices, it was convertible into consumption by way of mortgages. What increases Denmark had experienced in affluence, education, and employment from 1990 to 2008, this group received comparably less of than the rest of the population. In the same period, the general shift towards the 'work-first' perception of welfare benefits in general - and social 
assistance in particular - was directed at exactly this residual group, underscoring the fact that they were not only left behind in respect of socio-economic development, but also in regard to inclusion into the moral community. The proposed 'misfortune' approach to trust is useful in understanding the gap between the empowered and disempowered which the general theories of generalized trust struggle with. While most theories of generalized-trust development do well in explaining the incremental increases in trust associated with increases in socio-economic position and background, they fail in explaining the shift between the inclusionary and exclusionary aspects of society. However, a misfortune theory of generalized trust would suggest that such a shift is to be expected, since exclusion is compound, making economic, social, and symbolic resources scarce simultaneously. If we consider generalized trust to express a positive outlook on social relations as cooperative and fundamentally unthreatening, those left behind in excluded mistrust are those who perceive social relations as being neither.

\section{References}

Anheier, H., \& Kendall, J. (2002). Interpersonal trust and voluntary associations: examining three approaches. The British Journal of Sociology, 53(3), 343-362.

Bateson, P. (1988). The Biological Evolution of Cooperation and Trust. In D. Gambetta (Ed.), Trust (pp. 14-30). Oxford: Basil Blackwell.

Christensen, R. S., \& Gundelach, P. (2011). Bilag [Appendix]. In P. Gundelach (Ed.), Små og Store Forandringer: Danskernes værdiers siden 1981 [Small and large changes: Danes' values since 1981] (pp. 284-291). Copenhagen.: Hans Reitzel.

Danmarks Statistik (2010a). BEF1A.

Danmarks Statistik (2010b). BEF1A07.

Danmarks Statistik (2010c). U10: Elever efter bopælskommune, uddannelse, alder og køn [Students by municipality of residence, education, age, and gender].

Delhey, J., \& Newton, K. (2003). Who Trusts? The Origins of Social Trust in Seven Societies. European Societies, 5(2), 93-137. 
Delhey, J., \& Newton, K. (2005). Predicting Cross-National Levels of Social Trust: Global Pattern or Nordic Exceptionalism? European Sociological Review, 21(4), 311-327.

Demant, J., \& Østergaard, J. (2007). Partying as Everyday Life: Investigations of Teenagers' Leisure Life. Journal of Youth Studies, 10(5), 517-537.

Edwards, R., Ranson, S., \& Strain, M. (2002). Reflexivity: towards a theory of lifelong learning. International Journal of Lifelong Education, 21(6), 525-536.

Frederiksen, M. (2012). Suspending the Unknown: The Foundations, Limits and Variability of Intersubjective Trust. Published PhD thesis, Dept. of Sociology, University of Copenhagen.

Fukuyama, F. (1996). Trust. Harmondsworth: Penguin.

Fukuyama, F. (2001). Social Capital, Civil Society and Development. Third World Quarterly, 22(1), 14.

Giddens, A. (1990). The Consequences of Modernity. Cambridge: Polity Press.

Giddens, A. (1991). Modernity and self-Identity. Cambridge: Polity Press.

Gundelach, P., \& Kreiner, S. (2004). Happiness and Life Satisfaction in Advanced European Countries. Cross-Cultural Research, 38(4), 359386.

Hansen, N. B., \& Gleerup, J. (Eds.). (2004). Videnteori, Professionsuddannelse og professionsforskning [Theory of knowledge, medium-length tertiary education, and research on professions]. Odense: Syddansk Universitetsforlag.

Hardin, R. (2002). Trust and trustworthiness. New York: Russell Sage Foundation.

Herreros, F. (2004). The problem of forming social capital. New York: Palgrave Macmillan.

Hooghe, Marc (2008). Voluntary associations and socialization. In D. Castiglione, J. Van Deth, \& G. Wolleb (eds.), The handbook of Social Capital Research (pp. 273-302). Oxford: Oxford University Press

Inglehart, R. (1971). The Silent Revolution in Europe: Intergenerational Change in Post-Industrial Societies. The American Political Science Review, 65(4), 991-1017. 
Inglehart, R. (1999). Trust, well-being and democracy. In M. E. Warren (Ed.), Democracy and Trust (pp. 88-120). Cambridge: Cambridge University Press.

Inglehart, R. (2003). Human values and social change findings from the values surveys. Leiden: Brill.

Kawachi, I., Kennedy, B. P., \& Glass, R. (1999). Social capital and self-rated health: a contextual analysis. American Journal of Public Health, 89(8), 1187-1193.

Knack, S., \& Keefer, P. (1997). Does Social Capital Have an Economic Payoff? A Cross-Country Investigation. The Quarterly Journal of Economics, 112(4), 1251-1288.

Kreiner, S. (1996). An Informal Introduction to Graphical Modelling. In H. C. Knudsen \& G. Thornicroft (Eds.), Mental Health Service Evaluation (pp. 156-175). Cambridge: Cambridge University Press.

Kumlin, S., \& Rothstein, B. (2005). Making and Breaking Social Capital: The Impact of Welfare-State Institutions. Comparative Political Studies, 38(4), 339-365.

Lewis, J. D., \& Weigert, A. (1985). Trust as a social reality. Social Forces, 63(4), 967-985.

Luhmann, N. (1979). Trust: A mechanism for the reduction of social complexity. in Trust and Power (pp. 4-103). New York: Wiley.

Luhmann, N. (1988). Familiarity, Confidence, Trust: Problems and Alternatives. In D. Gambetta (Ed.), Trust (pp. 94-107). Oxford: Basil Blackwell.

Mannheim, K. (1952). The Problem of Generations. In P. Kecskemeti (Ed.), Essays on the Sociology of Knowledge (pp. 276-323). Oxford: Oxford University Press.

Miller, A. S., \& Mitamura, T. (2003). Are Surveys on Trust Trustworthy? Social Psychology Quarterly, 66(1), 62-70.

Misztal, B. A. (1996). Trust in modern societies. Cambridge: Polity Press.

Möllering, G. (2001). The Nature of Trust: From Georg Simmel to a Theory of Expectation, Interpretation and Suspension. Sociology, 35(2), 403-420.

Newton, K. (2001). Trust, Social Capital, Civil Society, and Democracy. International Political Science Review/ Revue internationale de science politique, 22(2), 201-214. 
Newton, K. (2004). Social Trust: individual and cross-national approaches. Portuguese Journal of Social Science, 3(1), 15-37.

Newton, K. (2008). Trust and Politics. In D. Castiglione, J. Van Deth, \& G. Wolleb (Eds.), The handbook of Social Capital Research (pp. 241272). Oxford: Oxford University Press

Nooteboom, B. (2007). Social Capital, Institutions and Trust. Review of Social Economy, 65(1), 29-53.

Paxton, P. (2007). Association Memberships and Generalized Trust: A Multilevel Model Across 31 Countries. Social Forces, 86(1), 47.

Pilcher, J. (1994). Mannheim's Sociology of Generations: An Undervalued Legacy. The British Journal of Sociology, 45(3), 481-495.

Putnam, R. (2000). Bowling alone. New York: Simon \& Schuster.

Putnam, R. D., Leonardi, R., \& Nanetti, R. Y. (1993). Making democracy work. Princeton: Princeton University Press.

Robinson, R. V., \& Jackson, E. F. (2001). Is Trust in Others Declining in America? An Age-Period-Cohort Analysis. Social Science Research, 30(1), 117-145.

Rothstein, B. (2000). Trust, Social Dilemmas and Collective Memories. Journal of Theoretical Politics, 12(4), 477-501.

Rothstein, B., \& Uslaner, E. M. (2005). ALL FOR ALL: Equality, Corruption, and Social Trust. World Politics, 58(1), 41-72.

Stolle, D. (1998). Bowling Together, Bowling Alone: The Development of Generalized Trust in Voluntary Associations. Political Psychology, 19(3), 497-525.

Uslaner, E. M. (1999). Trust but verify: social capital and moral behavior. Social Science Information, 38(1), 29-55.

Uslaner, E. M. (2000). Producing and consuming trust. Political Science Quarterly, 115(4), 569-590.

Uslaner, E. M. (2002). The moral foundations of trust. Cambridge: Cambridge University Press.

van Oorschot, W., Arts, W., \& Gelissen, J. (2006). Social Capital in Europe: Measurement and Social and Regional Distribution of a Multifaceted Phenomenon. Acta Sociologica, 49(2), 149-167. 
Vicky, C. (2001). Poor people, poor places, and poor health: the mediating role of social networks and social capital. Social Science \& Medicine, 52(10), 1501-1516.

Whelan, B. J., \& Whelan, C. T. (2004). In What Sense is Poverty Multidimensional. In G. Room (Ed.), Beyond the Threshold: The Measurement and Analysis of Social Exclusion (pp. 29-48). Bristol: The Policy Press.

Yamagishi, T. (2001). Trust as a Form of Social Intelligence. In K. S. Cook (Ed.), Trust in Society (pp. 121-145). New York: The Russell Sage Foundation. 